\title{
Foundations Of Service Science Concepts And Facilities
}

Harry Katzan, Jr., Savannah State University, USA

\begin{abstract}
This paper gives a conspectus of Service Science for academicians and practitioners with the express purpose of defining the scope of the discipline. The subject of services is the up and coming discipline for the $21^{\text {st }}$ century, and it encompasses technology, entrepreneurship, business growth, and innovation - four subjects that are generally of interest to most managers and scientists, alike. Services are important to people in business, government, education, health care and management, religion, military, scientific research, engineering, and other endeavors that are too numerous to mention, because most service providers - be they individuals, businesses, governments, and so forth-are also consumers of services. This is the first of three introductory papers on the subject. The second paper, entitled "Foundations of Service Science: Management and Business" covers the operational environment for services, and the final paper entitled "Foundations of Service Science: Technology and Architecture" covers the technical and architectural basis for the Service Science discipline.
\end{abstract}

Keywords: Service science, service system, service characteristics, business service, service facilities, outsourcing, electronic business, information services.

\section{HISTORICAL OVERVIEW}

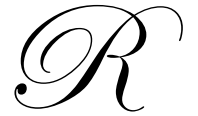

ecognizing that more than $80 \%$ of the country's GNP results from services and also that more than $80 \%$ of the workforce is employed in services, Sam Palmisano, CEO of IBM, initiated a corporatewide program in Service Science that has transformed IBM and many other organizations. The cornerstone of the program is the fact that even though most of us are engaged in services, we really know very little about the subject. At the time, there was no academic subject called "service science," no principles of service science, no theorems, and most importantly, there was no set of best practices. He has changed all of that. An important aspect of the IBM initiative is that it has enabled academic participation in the development of the subject matter through the establishment of a field called Service Science in a similar manner to the way IBM assisted in the development of academic programs in Computer Science, three decades ago. Responding to this situation, the IBM Corporation initiated a project in the years 2004-2007 to develop a science of services. The project has resulted in tidal wave of activity within the business and university communities to study the subject and develop academic programs. With Service Science, we are interested in the underlying principles that define the subject matter and demonstrate its relationship to other disciplines.

Service Science has the potential to change the way we think about and subsequently view the new world order and may eventually change the predominant economic focus from products to services. Since services are the cornerstone of most modern businesses, there is a high level of interest in the subject by persons from business, government, and education. Major corporations have supported intellectual activity on the subject by giving introductory presentations at many conferences and by providing liberal access to relevant information on corporate Web sites. The subject of service science has been addressed in papers in most business and computer conferences, usually in the area of service management and service marketing because a clear description of exactly what constitutes service science has not heretofore been available. 


\section{SERVICE CONCEPTS}

This section gives an overview of Service Science for academicians and practitioners with the express purpose of defining the scope of the discipline. Many of the basic concepts are commonly known or easily acquired - especially if a person thinks about them. Some of the concepts you just never think about.

\section{Service}

A service is generally regarded as work performed by one person or group that benefits another. It is an activity and not an element of property. Another definition is that it is a type of business that provides assistance and expertise rather than a tangible product. Still another definition is that it is after-purchase support offered by a product manufacturer or retailer. In employment, it is work done for business as an occupation. We are going to refer to it as a provider/client interaction in which both parities participate and both parties obtain some benefit from the relationship. The provider and the client exchange information and adopt differing roles in the process. A service is a form of activity, consumed at the point of production.

Normally, an element of service is a process - or a diverse collection of activities - applicable in principle to business, education, government, and personal endeavors.

\section{Service System}

A service system is a socially constructed collection of service events in which participants exchange beneficial actions through a knowledge-based strategy that captures value from a provider-client relationship. The definition is based on the notion of a system, which is a group of interdependent components that form a coherent whole and operate together to achieve a purpose.

The inherent service strategy is a dynamic process that orchestrates (or coordinates) infrastructure, employees, partners, and clients in the co-production of value. Based on a theoretical framework for creating economies of coordination, research on service systems incorporates a detailed analysis of various and diverse service events, so as to develop a view of the servicescape.

\section{Service Science Abstraction}

Service science is an abstraction of service systems in the same way that computer science is an abstraction of computer-based information systems. The procedure, in both cases, is to take a piece of an existing system and put it under the microscope of academic scrutiny. In this particular instance, we are taking a service centric view of enterprise systems and economic activity, where traditional enterprise functions are candidates for being packaged as enterprise services.

\section{Service Characteristics}

The concept of service has its roots in economic activities that are classified as extractive, secondary, and services. Extractive refers to agriculture, mining, forestry, fishing, and so forth. Secondary refers to manufacturing and processing. Services refer to everything else, usually subdivided into domestic, trade and commerce, information services, and personal. This is a very general definition intended for the reporting by the government of economic conditions. In order to get a handle on services, we need better definitions.

A service is a provider/client interaction that creates and captures value. A unique characteristic of services, unlike agriculture and manufacturing, is that both parties participate in the transaction, and in the process, both capture value. In a sense, the provider and the client co-produce the service event, because one can't do without the other. It stands to reason that the roles of the client and the provider are different. In a doctor/patient service event, for example, the physician brings knowledge, time, and the necessary infrastructure. The patient brings him or herself, a medical history, and a perceived situation that requires attention. During the service 
process, the participants exchange information in various forms, resulting in a change to the people involved. The doctor's experience level and assets change, as do the patient's information level and physical or mental condition. There is more to it, of course, but this is the basic idea.

\section{Service And Organizations}

For organizations, the case is slightly different. Some companies, such as professional firms, are totally service oriented. Other service companies, such as airlines and restaurants, have more complicated arrangements. An airline company, for example, could contract out its telephone reservation service to another company. This process is called outsourcing.

Continuing with the airline example, let's assume that an agreement is made with a company in another country to run a call center whereby passengers can make reservations and obtain information. The airline is the client and the call center company is the provider. How does the client (that is the airline company, in this case), who is a stakeholder with something to gain or lose, effectively control the situation? They collectively draw up a service level agreement that governs the quality of service, the number of calls to be handled in a specified period of time, the duration of the agreement, and the costs involved. Why don't the patient and the doctor have a service level agreement? They do, but it is implicit in the social setting in which medical services are performed. In many areas of service management, the key element is the service-level agreement.

In government, services are governed by convention and law. Constituents use governmental resources for information and a variety of physical services. In many cases, it is difficult to tell who is providing the service and who is receiving it. In education, the provider/client relationship can be complicated. Who is the provider and who is the client? Let's assume that the teacher provides the service to the student, by giving lectures and managing classroom activity. But it could be more complicated than that. Consider a university setting. Does the professor provide a service to the administration by teaching courses and doing the myriad of other things faculty do? But then again, one could look at it the other way around by contending that the purpose of the administration is to provide service to the faculty and students by supplying the educational infrastructure. So the teacher could be a provider of services and a client of services, at the same time.

\section{Business Service}

Some firms further complicate the picture by essentially being in two related service businesses at the same time. Consider an information technology (IT) company that provides services in two forms: consulting and outsourcing. With consulting, the firm tells a client how to do something, and with outsourcing, the firm does it for the client. As an example, the IT firm could advise on what information systems the client needs and then develop those systems. Similarly, it could provide information on how to set up an IT operation and then run that shop after it is set up.

Related to IT services is a general class of activities known as business services. With business services, like IT services, there are two options: consulting and outsourcing. With business service consulting, organizations are advised about business function, such as customer relationship management (CRM) and enterprise resource planning (ERP). With outsourcing, the business services firm does it for you - perhaps in the areas of finance and accounting.

What we have at this point are multiple organizations, collections of people and technology connected by value propositions and shared information, operating as a service system. More specifically, a service system can be viewed as a configuration of people and technology connected to another system of people and technology in order to co-create value for both organizations. 


\section{Differences Between Products And Service}

It is useful to consider the differences between products and services. Products are tangible and services are intangible. An automobile, a garment, a table, and even a fast-food hamburger are examples of products. A doctor's visit, swimming pool cleaning, and package delivery are examples of services. On the surface, one could conclude that products are produced through some relevant sequence of operations, but that is not a defining characteristic, since most services also go through a sequence of steps. The answer is that a product is an artifact something you can see or touch. Clearly, a service results in something worthwhile - otherwise, why engage in it but the result is a change in a person or possession, not in the creation of something.

Products are storable; services are non-storable. You can store any of the examples of products, given above. If you have your car cleaned or your lawn mowed, you can't exactly save that service. When a service is finished, it is done forever. Perhaps, a record of the service is archived, explicitly or implicitly, but once the stop button is pushed, that service machine is off. If a service has to be repeated, then it is another service event.

Another related difference is that services are generally regarded as perishable. The implication here is that if a seat on an airline flight is not used, then the value of that opportunity is lost. There are many parallels between services and events in everyday life. If you buy a fresh banana and don't eat it within a reasonable time period, its value is lost. You can buy another, but again, that is a different thing.

With products, consumption follows production. In fact, the build-store-sell and the sell-build-ship business models apply here. With services, consumption and production occur at the same time. This characteristic is related to the difference between product quality and service quality. With products, a quality assessment can be made before the customer enters the scene. With services, the client's view of quality is determined during the service process. As product classes mature, they become standardized and competition shifts to price. Services are almost always customized. In general, product development is capital intensive, and the delivery of services is labor intensive. It is important to recognize, however, that the creation of products may include services in the production process, and that services may also accompany production in the form of follow-on activity.

\section{Classification Of Services}

Given that services are pervasive in modern economies, there would appear to be so much diversity between them that it would be impossible to make any sense of the subject. On the other hand, there has to be a set of common denominators that we could use to classify services so that we could draw some conclusions about organization, performance, and quality.

Services are generally classified by at least five criteria: service process, service nature, service delivery, service availability, and service demand. The major factor is a qualitative concept, known as "service nature" that consists of service object and service result. We will focus on the service object, because it reflects whether a service is performed on a person, a possession, or information. In a previous section, we covered the subject of distinguishing services from goods. The service object is useful for distinguishing services from services, and it preserves the roles of the provider and the client. In a generic sense, the question of who or what gets the service is the determining factor in exactly how much of the other four criteria are applied to a particular service event.

\section{People Processing Service}

In people processing services, the provider performs corporeal actions to the client. The client is part of the service production process and remains in the domain of the provider during service delivery. There is simultaneity of production with consumption in a people processing service event, and the provider and client, are regarded as co-producing the service. Various forms of transportation service, for example, are placed in this category. 


\section{Possession Processing Service}

In possession processing services, the provider changes the state of one or more tangible objects under the jurisdiction of the client. Many possession processing services are straightforward, as in car washing and other maintenance activities. These services relate to the condition of an object and are regarded as physical services. Clearly, there are other attributes of service objects and one of the most common is ownership that puts retailing into the domain of service processing. In fact, some manufacturing operations consist of a sequence of services applied to a physical object or system. Another physical attribute is location, and an operation that provides components to a just-in-time production process is a form of service. Package delivery, for example, is a form of possession processing.

\section{Information Processing Service}

Information processing services deal with the collection, manipulation, interpretation, and transmission of data to create value for the client. Accounting, banking, consulting, education, insurance, legal, and news are commonly experienced examples of information processing services. There are important issues with information processing services, such as representation (as with lawyers and accountants), infrastructure (as with computers, databases, and the Internet), and self service (as with online facilities, ATM machines, and other administrative functions).

\section{Characteristics Of Services}

In spite of the prevalence of services in everyday life, the subject is rarely considered and seldom defined. In business, services are commonly referred to as the non-material equivalent of a good. Services can be sold, purchased, and scheduled. To many people, a service represents something they cannot do themselves or do not want to do, or perhaps more importantly, something that can be done more efficiently or in a less costly manner by a specialized business entity. Here are some characteristics of services:

\section{A service is a process.}

This notion is paramount to recognizing the far-reaching importance of service science as an academic discipline. A service takes input and produces output. In between the input and the output, there exist one or more steps that constitute the service process.

\section{A service is heterogeneous..}

This characteristic reflects the fact that each client/provider interaction in the form of a service event is unique.

\section{A service captures value.}

A service event creates a benefit to both the client and the provider, in the form of a change of state that is reflected in their physical condition or location, a change in their possessions, or in their assets.

\section{A service cannot be inventoried.}

The notion of opportunity loss is fundamental to service science. An empty seat on an airline flight cannot be resold. The value lost to a service provider due to a missed appointment cannot be regained. This characteristic gives a time dimension to services. Thus, a service capacity is said to be perishable, referring to the fact that it is "perished" when unused. 
A service is intangible.

A service event does not produce a physical product as a result; however, a service can produce a noticeable result.

A service is consumed at the point of production.

This characteristic adds specificity to the recognition that a service is a process, even though it may be summarized for descriptive purposes as a service event. When a service terminates, it is finished. After the final step in a service process, the event is archived along with the consequent change of states of the client and provider.

A service cannot be resold or given away.

It is not possible to pass a service on to another economic entity. The result of a service event is unique to that event, although information gained during the service process could theoretically be used by another entity. However, information resulting from a service event is not the same as the service event, because of the consumption characteristic.

A service is co-produced.

This characteristic emphasizes the fact that because of the simultaneity of client and provider participation and the fact that a service event does not result in the production of a good, but rather in the state of something, it is commonly referred to as the co-production of value in the sense that if either of the participants were not present for the service event, it could not be interpreted as being a service.

Service characteristics are useful for distinguishing one service event from another and for defining classes of services.

\section{SERVICE SYSTEM CONCEPTS}

A service system is a collection of resources and economic entities, capable of engaging in or supporting one or more service events. The resources are the infrastructure and other facilities necessary to support the service process. The economic entities are the service provider and service client that co-produce the service event. In the case of possession processing services, the service environment would also consist of one or more tangible objects that serve as the service object of the service process. In most cases, a service system is required to sustain a service event. Figure 1 suggests a service system. ${ }^{1}$ In this instance, the service target could be the client, a possession of the client, or an individual or an organizational entity over which the client has responsibility.

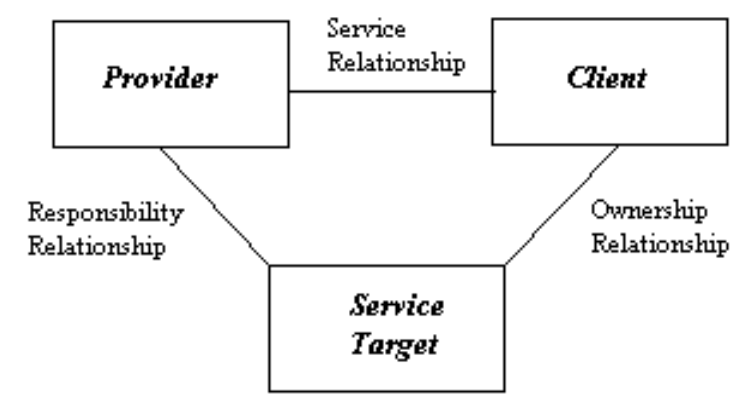

Figure 1: Systems View of the Service Relationship

\footnotetext{
${ }^{1}$ Adapted from Maglio, P.P., Service Science, Management, and Engineering (SSME): An Interdisciplinary Approach to Service Innovation, IBM Almaden Research Center, http://almaden.ibm.com/ssme, p. 14.
} 


\section{Service Facilities}

If a service provider and client can co-produce a service event, there must be some degree of geographical locality to the situation, in the sense that the client travels to the provider or the provider travels to the client or the client and provider execute the service event in a third-party location or they communicate via some form of interactive device and its corresponding media. In other words, they have to get together.

\section{The Service Factory.}

Let's first consider the case where the customer travels to facilities associated with the provider, such as an airline terminal, hospital, restaurant, retail establishment, or hotel - to name only a few examples. We will refer to the provider facilities, in this case, as the service factory. The basic idea is that the customer remains at the service factory during service delivery.

The situation quickly gets complicated because it depends on whether or not the service is associated with a tangible object, an intangible object, or a production supply chain. A pure service is a service not associated with tangible objects, such as in medical treatment, hair coloring, and personal transportation. The service event is scheduled, initiated, terminated, and archived - all in the service factory. Many service processes are comprised of several steps called the service chain. Other services, not just pure services, consist of a service chain, but this characteristic is normally associated with pure services. When a service process consists of a service chain, it is said to be "scripted." Clearly, a service script may be implicit in the service, such as a doctor's visit, or it may be explicitly prescribed as part of a formal service agreement. Depending upon the complexity of the situation, services can also be a part of a goods production process or a conventional supply chain.

A related consideration is whether the service is classified as being discrete or continuous. A discrete service takes place in s short time interval - such as hours. A continuous service takes place over a longer period of time - such as days or longer. Moreover, a continuous service may be comprised of several service events, as in insurance or banking. Hospital service is continuous consisting of a series of service events. Moreover, the service events may be dynamic in the sense that they are not necessarily planned beforehand. A doctor's visit, on the other hand, ordinarily consists of a service chain of planned events, wherein the services might include check in, get weighed, interact with the physician, and so forth. Some continuous services, such as insurance and banking, incorporate a service factory that is closely associated with the provider but not the client. Clearly, services of this type have a service initiation, service steps, and eventually a termination; but in-between service events are dynamic in the sense that they may occur on an unscheduled and unplanned basis.

Still other services in this category may utilize more than one service facility, such as a check-in terminal and a transportation vehicle. However, the classification applies since the client occupies provider facilities for the duration of the service. Branch banking is a form of continuous service with more than one service facility.

\section{The Service Shop.}

Some services involve leaving a possession of the client at a service shop for later pick-up, as in the cases of dry cleaning and auto repair. Clearly, the service shop is associated with the service provider, and the service object, owned by the client, occupies physical space in the service facility for the duration of the service process. Child day care, for example, would be placed in this category.

\section{The Service Portal.}

Other services engage a virtual service facility for the duration of the service event. All of this sounds like the Internet, and that's the idea. However, the category also includes telecommuting and a variety of online and telephone services. In fact, any activity, generally classed as e-Commerce, falls under the umbrella of a service portal. Included in the category of service portals are a variety of information services and "do it yourself" activities. 


\section{Mobile Service Facilities.}

In the previous categories, the emphasis has been on provider resources that occupy a fixed space, incorporating personnel, buildings, equipment, machines, vehicles, and supplies. The scenario has been that the client travels to the service facility or accesses it via some modern convenience. In other cases, the client moves as in navigation services and various forms of satellite communication, such as radio, information providing, and related services - such as car unlocking.

\section{Client Facilities.}

The subject of service provisioning would not be complete without the mention of client facilities, as in the case where the service provider travels to the client to perform a service. In most instances in this group, the service is performed on a possession of the client - even though that is not a necessary condition.

\section{Service Implementation}

All organizations and all persons do not have the same service requirements and accordingly, the same problems. Moreover, it is impossible to look at services from solely an industry perspective or even a personal point of view. Clearly, services differ between industries and between persons. On the other hand, the diverse set of activities universally called services wouldn't be called services if there weren't some degree of commonality among them. Accordingly, we are going to take a look at steps in the service process, not necessarily service interactions, per se, that are commonly incorporated into the service chain.

Service initiation refers to the steps necessary to schedule a service and establish a provider/client interaction. Appointments with professional service providers are normally scheduled, whereas arrangements with nonprofessionals are commonly scheduled on an informal basis. Some service providers use appointments to manage demand as a means of achieving service efficiency. Entry service administration initiates customer input, such as filling out forms, and establishes a service agreement encompassing fees and expectations. Legal documents may be involved with this step, and client requirements are delineated. Service interactions are the steps in the service process. For discrete service processes, service interactions are statically planned with expected variations, since most services are customized by the provider for each client. For continuous service processes, service interactions are dynamically engaged - as in the case of banking, insurance, and hospital care. Service termination represents the end of a set of service interactions, regardless if they are statically or dynamically executed. Followon services or referrals are established during this step. Exit service administration initiates the record-keeping process and deals with the economic aspects of the service process. Service archiving handles information storage and legal requirements.

Collectively, the six generic functions are normally present, explicitly or implicitly, in practically all service processes, and are referred to as the service platform. The intended meaning of the terminology is that the service platform supports the service process.

\section{Business Service Systems}

The basis of business service systems is the evolution from collaboration to automation, as suggested by Figure 2. ${ }^{2}$ The first phase, entitled Collaboration, utilizes human engineering principles and is characterized as "assistance by doing some of the work." The next phase, entitled Augmentation, utilizes technology to increase productivity by using tools to supplement human activity. The third phase, entitled Delegation, is the outsourcing to service providers of non-core business processes that do not provide competitive advantage. The final phase, entitled Automation, employs technology to provide self-service systems. Employing the four elements of business service systems, namely organization, technology, management, and information systems, service businesses can

\footnotetext{
${ }^{2}$ Adapted from Service Science, Management, and Engineering (SSME): Challenges, Frameworks, and Call for Participation, IBM Almaden Research Center, http://almaden.ibm.com/ssme, p. 13.
} 
move among the phases by considering the following elements: business value (Should we?), technology (Can we?), governance (May we?), and business priorities (Will we?).

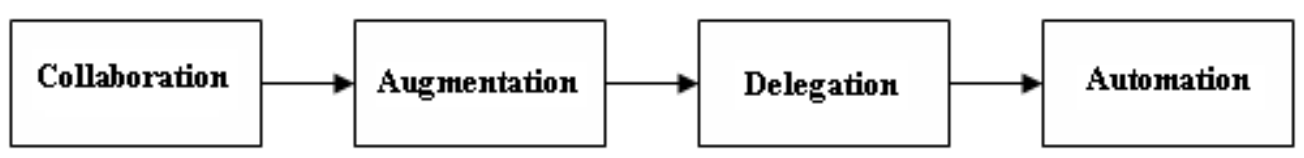

Figure 2: Business Service System

\section{Globalization}

A business service system is a complex socio-techno-economic system ${ }^{3}$ that combines people, technology, value, and clients along four dimensions: ${ }^{4}$ information sharing, work sharing, risk sharing, and goods sharing. There is some evidence that some elements of all four dimensions are present in all business service systems. Before globalization, services were performed between provider and client with some degree of locality. After Globalization Three ${ }^{5}$, business value creation through services is created by sharing. Information and communications technology (ICT) is the key business driver in value creation and is the form of technology most closely aligned with business service systems.

\section{Outsourcing}

Outsourcing is the transfer of the ownership of a business process to a supplier, which includes management and day-to-day execution of that function. ${ }^{6}$ The most commonly outsourced business processes are information technology, human resources, accounting, customer support, and call center operations. The key characteristics of outsourcing are "transfer" and ownership; it is different from the process in which the buyer retains control and tells the supplier how to do the work. The objective of outsourcing can be and often is one of the following: reducing costs, focusing the capability of a particular business on more profitable activities, and to obtain special capabilities that the provider firm may possess. Core business competencies are usually not outsourced. For example, airlines commonly outsource telephone reservation and information systems to foreign companies in order to reduce costs and focus on flight operations. Another example, more close to home, is the outsourcing of business cleaning services to benefit from economies of scale for that type of service.

With outsourcing, the client and the provider enter into a business relationship, established with a substantial business agreement, and then the service provider takes over the business process. Outsourcing is usually - actually, almost always - associated with offshoring, but that need not necessarily be the case.

\section{Offshoring}

Offshoring is a general term that describes the relocation of a business process from one country to another. ${ }^{7}$ Although the present context is services, the practice also applies to manufacturing and production. If a country can provide services in a less expensive manner than other countries, it gives them a comparative advantage to freely trade those services. In the modern world of ICT for the appropriate services, therefore, offshoring can be achieved by establishing the necessary business ecosystem.

\footnotetext{
${ }^{3}$ Maglio (2007) op cit. p. 22.

${ }^{4}$ Maglio and Spohrer (2007), p.4.

${ }^{5}$ Friedman, T.L. (2006), p. 10.

${ }^{6}$ Wikipedia gives a good description of outsourcing along with a comprehensive list of references and links.

${ }^{7}$ Wikipedia gives a good description of offshoring along with a comprehensive list of references and links.
} 
To be more specific, offshoring is the practice ${ }^{8}$ of transferring an internal business process of a company in one country to another country, to be executed by the same or a different company. Service offshoring is particularly appealing to modern business since many services can be digitized thereby facilitating inter-country relocation.

Offshoring may involve the transfer of intellectual property and training to the receiving country and is related to the availability of educated and trained labor as factors in production - the others being land and capital. According, many design and development services are being redirected offshore.

\section{Outsourcing And Offshoring}

It follows from the above discussion that a company that engages in the transfer of an entire business function to another company in another country is both outsourcing and offshoring. As mentioned previously, common examples of outsourcing are call centers, accounting, customer support, human relations, and information technology (IT). It is now appropriate to add medical diagnosis, design services, and engineering services to the list and recognize that both outsourcing and offshoring are involved.

Public opinion on combined outsourcing and offshoring $(\mathrm{O} \& \mathrm{O})$ is negative, because it is generally felt that the process adversely affects individuals and the total labor market. Even in cases in which O\&O is associated with lower jobless rates, it is felt that $\mathrm{O} \& \mathrm{O}$ tends to shift displaced workers into lower paying jobs.

\section{Transformational Outsourcing}

Many executives feel that outsourcing allows the firm to concentrate on core competencies and, in the case of ICT, achieve greater flexibility. Because many business processes are totally dependant upon computers, business agility is necessary for developing responsiveness in the marketplace. Transformational outsourcing refers to the combination of cost saving with the potential for strategic flexibility and supplements cost focus with opportunity focus.

The underlying idea is that through transformational outsourcing, the firm will be transformed into one with the requisite characteristics. Innovation in supplying services is required, therefore, because services are almost always customized and are labor intensive. Moreover, competition in the services marketplace does not tend to drive down process and profit margins. The key point, of course, is that outsourced services do not usually provide differentiation in the marketplace.

\section{Sharing}

The major tenet of services is that the provider and the client co-produce a service event and the composite interaction creates value for both of the participants. To a greater or lesser degree, a service is enacted by sharing, as covered previously. ${ }^{9}$ Information sharing is more closely aligned with services in which persons interact, such as medical provisioning and consulting. Work sharing is characterized by outsourcing. Risk sharing (although not covered so far) is associated with continuous form of service, such as insurance, and is related to transformational outsourcing. Goods sharing is involved with certain formal tangible people-oriented services, such as hotel and auto rental.

\section{Service Process Organization}

Practically everyone has heard of or experienced service providers that traditionally have clients backed up with very long waiting times. Another common example is the "not so fast" fast-food restaurant. In the world of services, organization is everything. While it is literally impossible to solve all service problems in a few pages, it is

\footnotetext{
${ }^{8}$ Use of the term "practice" is by intention. It is meant to denote that the process is prevalent.

${ }^{9}$ Maglio and Spohrer (2007), ibid.
} 
feasible to deliver an organizational design that is relevant to most service systems. A definition of a service system is:

A service system is a system of people and technology that adapts to the changing value of information in the system.

It is important to emphasize that the "changing value of information" also refers to the service process itself. So it should be expected that a particular service organization would adjust to changing conditions in the workplace.

In the production of goods, a measure of organization is the level of inventory, even though the management of inventory can be a subject in its own right. With services, capacity is a key element, and long waiting lines are evidence of insufficient service capacity, ineffective demand management, or inadequate organization. In this section, a working model of service organization is presented that should serve as a starting point for looking at organizational issues.

\section{An Example - Retailing And Services}

The importance of service organization is inherent in retailing. Retailing is a service, as covered previously, and the sales service event changes the ownership attribute of a product. A significant aspect of retailing exists, however, that is associated with service organization.

There is a component in retailing that is directly related to the level of expected service as a function of the price of the product. Most customers possess a nominal price for a given product. If the sales price is lower than nominal value, then less service is expected. If the sales price is higher than the nominal price, then more service is expected or the product is deemed overpriced. Buyer behavior, therefore, is governed by a combination of price and retail service, so that buyer behavior is influenced to some degree by service organization. ${ }^{10}$

\section{INFORMATION SERVICE CONCEPTS}

Through information and communications technology, modern society has made enormous advances in how we live and work. How far we have progressed is summarized by Microsoft chairman Bill Gates in a recent email message. "The ability to access and share information instantly and communicate in ways that transcend the boundaries of time and distance has given rise to an era of unprecedented productivity and innovation that has created new economic opportunities for hundreds of millions of people around the world and paved the way for global growth that is unparalleled in human history.",11

An information service is a resource capable of supporting a service event or instantiating a service event based on information. In other words, an information service can assist in the execution of a service, such as in retailing, or it can actually be the service as when buying a pair of shoes on the Internet - actually, the World Wide Web, but that distinction is not required at this point. The resource is a service provider that can take the form of a person or a computer. The execution of an information service event requires a service client that can also take the form of a person or computer, and the provider and client must interact in order to co-produce the service. The execution of a service event changes the state of the provider and the client, but a tangible object is not produced. An information service is commonly associated with computer technology, but that is not a necessary condition. The most definitive characteristic of an information service is that the information travels, which gives rise to new models of information management and communications technology.

\footnotetext{
${ }^{10}$ Conversation with William Dowling.

${ }^{11}$ Gates, B. (2007), The Age of Software-Powered Communications, Electronic Mail Message, October 16, 2007 1:03:06 PM EDT.
} 


\section{A Personal Dimension}

Most of the information that is communicated between people is about something. Clearly, there is some form of informational interchange that accompanies practically all services. Information service is more than the incidental exchange of information.

With information services, the client specifically requests information and the provider supplies it using some form of communications channel. The service request may be implicit in some other form of activity or it may be "ordered" on a demand basis, but it is nevertheless requested.

\section{Data Versus Information}

Each provider/client interaction in an information service requires a context, and here is why. Pure unadulterated facts are known as data. Information is data in a particular context so it has a specific meaning. When you request some information about a subject from an Internet web site, for example, the context is supplied in some manner, such as from the site itself, the nature of the query, or even information in a previously requested web page. The context effectively gives meaning to data and turns it into information. The bits that flow through wires or through the air as electromagnetic radiation are nothing more than data, at best. Accordingly, it would be proper to say that it is an information service that turns a bunch of bits into something useful, such as a news story or downloaded music.

\section{Ordinary Mail}

Not all information services necessarily require a computer. The United States Postal Service is a case in point, as is its international equivalent, known as the PTT (Post, Telephone, and Telegraph), which do not require a computer in their basic form. Electronic mail (email as we generally know it) is also an information service, and it does require a computer. Each element has a sender and an intended recipient. Who is the service provider? It is certainly not the sender or recipient. Clearly, it is the mail service itself. The mail serves as the communications channel between the sender and the recipient. In most other information services, the communications channel is only a channel for communication and nothing more. With mail service, pickup, transportation, and delivery would appear to be the service, and the informational content of the message is not brought into the analysis.

\section{Is Software A Service?}

Yes. Software would appear to be a service, such as in document preparation and as suggested by the example of ordinary mail. Information is moved from one place to another and perhaps it is transformed a bit in the process. In document preparation, or word processing, as it is usually called, information is moved from an origin, such as a person's brain, through the nervous system, the person's fingers, and the keyboard to the computer and software and then to a document file. Nevertheless, it is transferred from one place to another. If electronic mail is considered to be a service, then it would seem that word processing is also. Consider another example. If you go to a tax preparation agency to have your return prepared, you consider it to be a service. If you buy a program for a small fee that does the same work as the tax agency, does it perform a service? Most people would agree that tax software is a service. In the same vein, presentation, spreadsheet, and database software would also be regarded as services.

There is another aspect to all of this, as exemplified by the word processing and email examples. The provider and client participate in the exchange of information, even though they may not be, and probably won't be, in close proximity. Thus, the distance metric is not necessarily significant in word processing, and in the case of email, even the time metric is also not significant.

Is all software a service? Perhaps, that should have been the original question. It is an open item. It is easy to conceptualize that office software for document preparation, presentation, graphics, data management, and data analysis could be regarded as services, since that software facilitates the transfer of information from one place 
to another. In the area of information systems, DSS (Decision Support System) software, for example, provides timely information to managers to aid in decision making. DSS software is definitely a service. What about AI (Artificial Intelligence) software, such as software that monitors gauges in a nuclear reactor? Then, if something goes wrong, the computer program shuts the reactor down before a meltdown occurs. Again, most people, especially those that work in nuclear power plants, would agree that it is a service. The debate could go on. For this paper, at least, software is a service.

Practically speaking, a software package, by itself, does not qualify to be an information service. In order to be functioning as a service, software must be operating on a computer in order to respond to a client's request in an appropriate manner. You always need a computer and communications infrastructure to support software services.

\section{Enterprise Information Services}

Information is the cornerstone of modern business, and government as well, and is the major ingredient in everyday commerce. In the study of information services, the distinction between information and the system to handle the information is often blurred. In this section, we will establish the difference between information and services.

A lot of information is about things: about a product or service, about travel arrangements, about how to do something, about an event, about a person or group, about something that has happened in the past, and so forth. We are going to refer to this type of information as operand information, and we are additionally going to refer to information that is involved with the service process itself as operant information. ${ }^{12}$ When the focus of an information service is the result, then as Vargo and Lusch might put it, we are using goods-dominant logic and the result is referred to as the operand. When the focus of an information service is on the process, then we are employing service-dominant logic and the operant resources are the information and the other steps in the service process.

\section{Business Information}

Business information services are usually divided into two categories: operational services and management services. Operational services are employed to run the enterprise and management services are used to manage the enterprise. Some of the same basic concepts are used in both categories, but the time and distance characteristics are different. For example, a database management system and a database are normally used to store persistent data for the enterprise. With operational services, the database is dynamic and is updated for each transaction. With management services, static data is needed to make effective decisions. Accordingly, a static database would ordinarily be created from the dynamic database so that timely management reports could be generated. Of course, this is a bit of a simplification, but the basic idea is there.

The management of information is an enterprise service in its own right. Clearly, the transfer of information from operational databases to a data warehouse is a concrete example of an enterprise information service.

\section{Transaction Services}

When you make an airline reservation or check a flight schedule using the Internet ${ }^{13}$, you are using a transaction processing system. Most information services that support operational systems in today's world use transaction processing. At the most general level, you interact with the server using the communications channel.

\footnotetext{
12 The distinction between operand and operant regarding services and associated information was developed by Vargo and Lusch (2004).

${ }^{13}$ You are actually using the World Wide Web, but this is a discussion for another venue. If you are going to New York, for example, do you say, "I'm going by car" or do you say "I'm going by highway"? Do you fly by plane or by air? The level of specificity is relevant to information services.
} 
You are the client, the server is the provider, and the service is the transaction. The entire process is mediated by hardware and software and the only thing that moves is the information.

\section{Client And Provider Input To An Information Service}

An information service requires client and provider input, just as in any other kind of service. Usually, the client - whether it is a person or a computer - enters a small amount of information into the service process. The provider - usually a computer information system - has access to a larger store of information, so that we can say the provider provisionally supplies a larger amount of information. The informational output of an information service is a function of the inputs and the nature of the service.

The client may have help supplying input to an information service through hardware and software facilities known as "interaction services." The provider may have assistance from database services and auxiliary services via a service bus.

\section{Interaction Services}

An interaction service is normally a socially-constructed collection of structural elements and behavioral patterns, such as action buttons, list boxes, and pull-down menus. Interaction services are dependant upon what the client expects to do with the information service. Here are some examples:

- $\quad$ Information exploration (e.g., find out about service science)

- $\quad$ Accomplish something (e.g., reserve a seat)

- $\quad$ Find a "good enough" answer to a question (e.g., how do we get to New York)

- $\quad$ Change the direction of a search operation (e.g., what about service systems)

- $\quad$ Establish a point of reference (e.g., mark my place to come back to at a later time)

Designing effective interaction services is not so easy ${ }^{14}$ but one approach is to think about the elements with which you have to work. A common set of such elements is composed of objects (such as icons), actions (such as a file menu), subject (such as the information that you have to work with), and tools (such as calendars and appointments).

Interaction services are a small part of service science, but nevertheless an important part.

\section{Service Bus}

A service bus is a high-speed data link between two computing platforms that operate in a request/response mode. The client requests an item of information (such as the price of IBM stock on Monday at 11:00 on a given date) and the provider, which operates in a server mode, supplies it in an expeditious manner. A service bus requires software that is called middleware.

An example of the need for a service bus is inherent in the following example. A stock broker is on a line to a client who requests the price of IBM stock. The brokerage firm has a computer (the server) that gets an up-tothe-second feed from the stock exchange. There is a high speed link between the stock brokers and the server, and each broker has a specialized thick client interface. The broker enters the stock symbol for IBM into a text box and clicks a send button. The server responds in a fraction of a second with the requested price.

\section{Collaboration}

Teams are the accepted norm in the modern enterprise, and collaboration is the process by which they progress toward a common goal. With information services, collaboration between groups and individuals can be effected from geographically dispersed locations. In general, collaboration has a well-defined structure and set of

\footnotetext{
${ }^{14}$ See Tidwell (2006) for a comprehensive reference to designing interfaces from a practical viewpoint.
} 
operational procedures that employs any or all of four recursive information service modalities: email, instant messaging, interactive media, and specially designed collaborative software.

Collaboration operates at the intellectual level and often benefits from decentralization and varying degrees of academic and personal diversity. Collaboration is a unique form of service. The service provider in the information service modality is established through information and communications technology, and is an instance of where the "service is the service provider," because it allows the clients in a collaboration service to exchange meaningful information.

Collaboration requires at least two clients interacting in what is referred to as a multiclient service. A multiclient service is frequently leaderless and is known as a virtual organization structure. Traditional workflow where a document is passed between team members is a common form of collaboration.

\section{Pull Versus Push}

It is perhaps a bit of an oversimplification, but "the manner in which you approach an information service determines what you get." The characteristics of the pull model are succinctly summarized in the following sentence. "Rather than 'push,' this new approach focuses on 'pull' - creating platforms that help people to mobilize appropriate resources when the need arises." 15

Push models are essentially scripted and thrive in stable environments with little uncertainty. Forecasting, as in demand forecasting, is key in push environments and allow high levels of efficiency to be developed in business processes. Most of modern business and governmental activity uses the push modality. A business pushes a product into the marketplace and people buy it. Push programs are top-down processes with the following steps: design, deploy, execute, monitor, and refine.

Pull models increase value creation for both clients and providers. For clients, "pull" activity expands the scope of available resources. For providers, pull systems expand the market for services. Pull platforms are associated with the following attributes: uncertain demand, emergent design, decentralized environment, loosely coupled modular construction of facilities, and on-demand service provisioning. Pull models are more amenable to uncertain business conditions.

From both the client's and the provider's perspectives, pull services focus on the following activities: find, select, purchase, deliver, and service. If all of this sounds familiar, it should be. It represents how you buy shoes on the Internet.

\section{Enterprise Service Constituents}

The seven constituents of an enterprise information service are providers, clients, messages, communications, information processing, persistent storage, and the user interface that collectively take into consideration the requisite technology including database facilities, email archives, protocols, business rules, operational procedures, and a variety of service interactions needed for enterprise applications. Since information and not people move in information services, this category of service is based on information and communications technology. It is important that when we discuss information services at the enterprise level, we are primarily concerned with functionality and not necessarily with computing platforms.

\section{Information Service Model}

Information service systems typically operate in a client/server mode, which means that the end user is the service client, the enterprise application running on a computing platform is the service provider, and the means of

\footnotetext{
${ }^{15}$ Hagel and Brown (2007) have identified the pull model as a means of establishing business resources for the upcoming generation of business activities based on mass communications and the Internet.
} 
client and provider interaction is some form of communications channel. Typically, the client enters information into the system through a well-defined interface and the provider does something in return. Exactly what the provider does is of primary importance to the information service system.

There are at least three distinct possibilities:

1. The provider accesses some form of persistent storage and returns selected information to the client.

2. The provider performs some element of information processing and returns an indicator to the client that it was done.

3. The client and the provider enter into an interactive dialog concerning specific informational elements and a supply chain operation is initiated to accomplish the corresponding enterprise operation.

As such, information service systems are instrumental in supporting daily activities. Typical enterprise applications are order processing, purchasing, accounting, inventory control, human resources, marketing and sales support, manufacturing, and various forms of service support including data collection and information management.

\section{Scope Of Electronic Information Services}

It is possible to be more definitive about electronic information services. Figure 3 depicts the three main constituents, introduced earlier, and how the information services are related. The diagram reflects the emphasis in electronic information services. B2C means business-to-consumer. B2B means business-to-business. G2B means government-to-business. C2C means consumer-to-consumer. G2G means government-to-government. G2C means government-to-consumer. In the symbols, the leftmost letter reflects the provider and the rightmost letter represents the client.

\section{Electronic Commerce}

Electronic commerce is an enterprise information service application supported by the Internet and the World Wide Web, and can be viewed as an opportunistic means of doing business with minimal cost. In short, the information services of the Internet and the Web are used to conduct business.

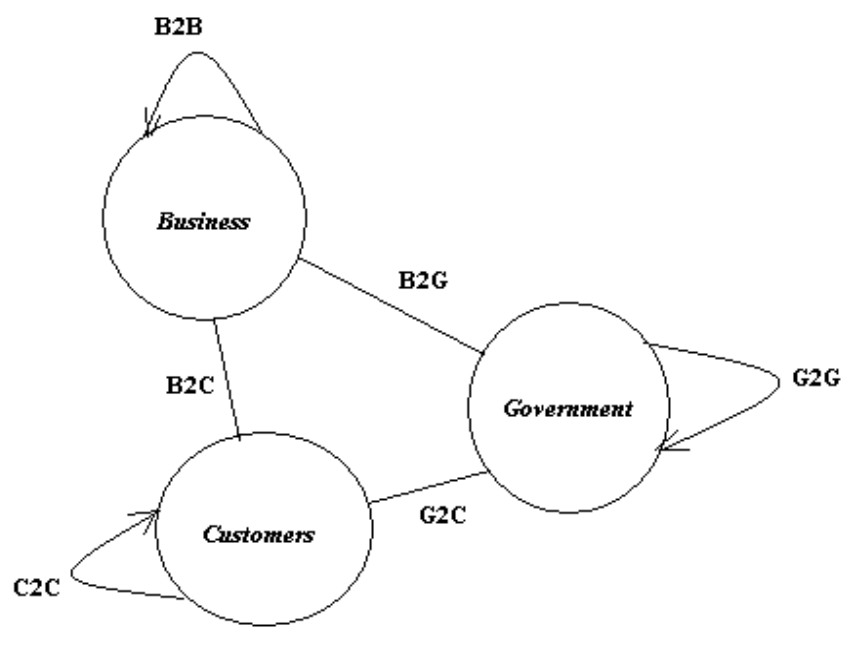

Figure 3: Scope of Electronic Commerce

Electronic commerce is usually known as e-commerce or B2C for short. Conventional business establishments are referred to as "brick and mortar" facilities characterized by a shopping area in which customers 
can view products, and business personnel can conduct commerce. The equivalent in the digital world is an ecommerce web site where a consumer can conduct analogous functions. The service provider is the e-commerce web site and the customer is the client connected to the web site via the Internet. In this instance, the Internet is the communications channel. The service process is the set of interactions between the customer and one or more web sites that go through the following steps: find, select, purchase, deliver, and service.

Find is an Internet service process, which is usually a set of service interactions, to navigate to the desired Internet retailer. After the electronic retailer is chosen, the select and purchase services represent the online equivalent of the traditional processes of making a purchase. Purchasing involves payment that invokes a secure service designed for that specific purpose. Deliver is another service process initiated by the retailer for physically delivering the product to the consumer. Service is the Web enabled service process of providing customer support. Each of the steps in the B2C service process (i.e., find, select, purchase, deliver, and service) involves at least one service, so the entire process can be properly regarded as a multiservice, driven by a series of constituent information services.

B2C transactions are characterized by increased convenience, enhanced efficiency, additional buying choice, and lower prices, from the consumer's perspective, and by an increased return on retailing investment for the electronic retailer. An electronic retailer need not have a related "brick and mortar" facility, but that is often the case.

\section{Electronic Business}

Electronic business is the use of the Internet and the World Wide Web to conduct business operations, including intra-business and inter-business transactions. This is a broad category and ranges from relatively simple information services to obtain tacit business information from within a single organization to complex Web Services and REST web services. ${ }^{16}$

Electronic business is usually known as e-business or B2B for short and has its roots in electronic data interchange (EDI) commonly used to exchange information on business operations within an organization, and between business partners, suppliers, and wholesalers. The use of the Internet for communications services reduces operational costs for computer networks and increases the value obtained from costs that are incurred.

The major advantage of B2B operations is that companies can utilize an information service known as the "B2B Electronic Marketplace," wherein they can buy and sell products and exchange information through a virtual marketplace. Not only can companies create supply chains, but they can create business partnerships in which one company can take advantage of information services of another company. The process, known as the componentization of information services, facilitates the creation of web services that allow the company to be a more responsive (to market and economic conditions) enterprise.

$\mathrm{B} 2 \mathrm{~B}$ is similar to $\mathrm{B} 2 \mathrm{C}$ in one respect. Modern company operations require the purchase of certain indirect materials, typically referred to as MRO materials, where MRO stands for "maintenance, repair, and operations," and include such items as ball pens, repair parts, and office equipment. Through the B2B electronic marketplace, various companies can collectively achieve lower cost through demand aggregation. Direct materials are items used in production or retail operations as part of a company's core business. B2B operations can also be sustained through web services.

\section{Electronic Marketplace}

Information services, such as the electronic marketplace, permit companies to engage in B2B market operations in horizontal and vertical electronic marketplaces. In a horizontal marketplace, buyers and sellers can

\footnotetext{
${ }^{16}$ Web Services and REST are covered under "Services Technology." REST stands for Representational State Transfer and is a means of conducting electronic business without an extensive Web Services infrastructure.
} 
interact across many industries. Travel and financial services are common examples, because they are applicable to almost any type of business, such as the process industries (oil and gas) and conventional and electronic retailing.

In a vertical marketplace, buyers and sellers are in the same industry and primarily engage in information services that relate to direct material.

\section{Electronic Government}

Information services are a means of transforming the management and operations of government to be more responsive, efficient, and reliable in delivering services to the electorate - at all governmental levels, including federal, state, and local communities. The objective is to enhance informational facilities that already exist so they may properly be regarded as click and mortar," with the options of obtaining information and services via the Internet and World Wide Web while continuing to have a physical presence. Three flavors have been identified: Government to Business (G2B), Government to Consumer (G2C), and Government to Government (G2G). In the latter case, there are two possibilities: inter-government and intra-government. Inter-government refers to the vertical alignment of information services between governmental levels on the same initiative, such as the coordination of federal, state, and local agencies on air pollution. Intra-government refers to the horizontal alignment of services between agencies at the same level of government, such as disaster response coordination between police, fire, and emergency medical departments.

Government to business operations reflect information services that cover purchasing of MRO materials, and the provisioning of information facilities for procedures, regulations, reporting, and compliance. In the latter case, governmental reporting facilities (by business to government) are commonly available to submit requisite documentation through Internet and World Wide Web services.

Most citizens are familiar with Government to consumer information services for taxes and various forms of registration. For taxpayers, the ability to download forms and directions, and the ability to submit completed tax forms is paramount. For those of us fortunate enough to receive a tax refund, the increased efficiency is money in the bank. Vehicle and voter registration are other information services that are efficient from both client and provider perspectives.

Overall, however, the availability of information on dates, procedures, directions, and so forth, at the click of a mouse via the Internet and the World Wide Web - pure information services - is the greatest advantage of G2C services.

\section{PERSONAL INFORMATION SERVICES}

Personal information services are an ever expanding collection of Internet and World Wide Web applications. The prevalence of the applications, however, brings up a fundamental question about exactly what constitutes the clients, providers, and the services in the various forms of information service. The resources appear to be different among the applications, so the presentation of the subject matter will be instructive for determining the scope of personal information services. Accordingly, we will cover the following services: chat rooms, instant messaging, Internet telephone, web auctions, user-generated media, social networking, and newsgroups. This is only a sample of relevant applications but is indicative of how information services are used to support those applications.

\section{Chat Rooms}

One of the most popular means of communicating on the Internet is through a chat room, the best known of which is IRC (Internet Relay Chat). IRC operates in the client/server mode and requires an IRC server; clients require special IRC software, usually downloaded from the Internet. 
When using chat, the user selects a channel, which establishes the conversation in which the user will participate. Characteristically, other users, throughout the world, will have chosen the same channel. The idea being that they will exchange information on a certain subject.

During operation, users type messages on their local client computer and the information is relayed via the Internet to the server. The message is then forwarded to other users signed on to the same channel and is displayed on their screens. A user may just listen, figuratively speaking, or may participate in the conversation. Ostensibly, users respond to other user's transmissions, so that an identifying name (sometimes called a handle) accompanies each submission. Since chat rooms are a global phenomenon, a network of IRC servers is required to service all of the users in a specific domain. A recent development is "voice chat," which is an audio equivalent to the traditional text-based chat.

At the end-user level, a chat room can be viewed as a collection of clients whose interpersonal communications is being managed by the chat server system operating as a service provider. The chat server system consists of the hardware, software, and Internet facilities, necessary to do the task. The service process consists of a set of dynamically determined client/server interactions, where the end-user is the client and the chat server is the service provider.

\section{Instant Messaging}

Instant messaging is the private real-time communication of textual messages between two users logged on to an instant messaging (IM) server over the Internet. Messages are forwarded through an IM server that uses the "sender" client's buddy list to determine the destination for forwarded messages. Many Internet specialists consider instant messaging to be a form of chat room operations, since it has similar information service characteristics.

\section{Front And Back Stages}

Internet chat and instant messaging, among other information services, incorporate a value chain of component services, divided between front and back stages. ${ }^{17}$ Essentially, the front stage is what the end-user conceptualizes and the back stage is what is going on under the covers, so to speak.

The noteworthy aspect of the division is that human clients are only part of the process, if they are involved at all, and the front stage represents the client's experience supplemented by the back stage that represents the information service support structure based on ICT facilities. The participants (Human or ICT) may possess different but complementary views of the service process.

\section{Internet Telephone}

Using the Internet for making telephone calls is appealing to many people because of the cost, which may be free in some cases, over and above the cost of the Internet connection. Several methods and associated software facilities are available. They generally fall into two broad categories.

In the first case, you use special hardware and software to communicate through your personal computer (PC) using a microphone and speakers. If you are calling someone who is also using the same method, the call is totally free, as it is with web browsing and email, and it is also applicable to users anywhere in the world.

In the second case, you use your ordinary "land line" telephone handset, and the call is routed over the Internet using a service process generally known as Voice over IP (VoIP). ${ }^{18}$ With VoIP, your voice is digitized and routed through the Internet as information packets, similar to other information services such as web pages and email. At the receiving end, the voice packets are converted to normal telephone signals.

\footnotetext{
${ }^{17}$ See Tabas (2007).

${ }^{18} \mathrm{IP}$ is the protocol for routing messages through the various inter-connected networks as packets of information. IP stands for Internet Protocol.
} 
With Internet telephone, the conceptualized front and back stages coincide. The clients are the telephone users and the service provider is the value chain of Internet activities.

\section{Web Auctions}

A web auction is an Internet and World Wide Web service that connects buyers and sellers in a consumerto-consumer (C2C) mode to conduct an online version of traditional auction. A well-known web site that manages the web auction process is $e$ Bay, but there are notably other sites that perform the same service.

In this instance, the information service is the posting and delivery of information concerning products for sale and associated bids. The clients are the buyers and sellers and the information service consists of the information processing facilities to sustain the auction. In this instance, the Internet and the World Wide Web serve only as a communication channel.

\section{User Generated Media}

There are three major forms of information dissemination normally originating from individuals that use the Internet and World Wide Web services: web logs, podcasts, and RSS feeds ${ }^{19}$. The services are related and are covered together in this section.

A web log (called a blog) is a medium for presenting information without restrictions or review over the Internet and accessible through the World Wide Web. People who participate in the service of creating information content in this category are known as bloggers, and the process itself is known as blogging ${ }^{20}$. The following three information services are normally associated with this form of activity: (1) Obtaining information on how to set up and access a blog web site; (2) Providing services that assist in actually setting up a blog web site; and (3) Using services that assist in making entries in a web log. Each blog site has a uniform resource locator (URL) ${ }^{21}$ and a theme, subsequently used for search and discovery.

A podcast is an audio blog, serviced by the Internet that serves the same purpose as a personal radio station. Using your PC and a microphone, you can record a document and store it on an appropriate blog site. Other users can then download the audio blog to their PC for listening or for transfer to a music player. Podcasts are used to listen to broadcast media and educational material. In the latter category, a podcast is an effective means of delivering course material to students.

An RSS feed is a means of generating a wider audience for blogs and podcasts, through an Internet technique known as Really Simple Syndication. RSS feeds utilize special web formatted material and deliver automatically generated downloads to registered end users using push technology.

User-generated media operations are generally considered to be a front stage process. All communications are asynchronous, which means they are created (or uploaded) as a process at one time and accessed (or downloaded) by another process at another time, using push technology.

\section{Social Networking}

Social networking is usually regarded as the process of keeping up with friends and family, and it is no surprise that the process has migrated to the World Wide Web. The inherent information service is social networking is known as "shared space."

A shared space is an online virtual public space in which a person - commonly a young person - can display information about themselves, including text, audio, and video. Special web sites, such as MySpace and Facebook, are designed to handle social networking. Actually, the video is predominantly photographs taken with a digital camera and uploaded to an appropriate web site set up for social networking. A person's virtual space is

\footnotetext{
${ }^{19}$ RSS stand for Real Simple Syndication.

${ }^{20}$ There is no name for people who just read web logs.

${ }^{21}$ A URL, such as www.ibm.com, is a means of accessing a web site.
} 
subsequently accessible by friends. The conceptual model for a shared space is that of a private room to which one can invite friends to look around, thus giving the owner a private virtual space not otherwise available in everyday life. As with information services that support media, social networking services are asynchronous and use pull technology.

\section{Newsgroups}

A newsgroup is a collection of people that participate in a discussion on a particular subject using Internet facilities. The usual form of communication is email, and the mode of communication is question and answer. The largest and most widely known online news group is usenet. A participant subscribes to a particular topic. When that participant $\operatorname{logs}$ on to the newsgroup server, the entries on the selected topic are automatically sent to that participant. Special client software is required to participate in a newsgroup. User interactions are organized by thread, so that a given user effectively engages in a conversation, as required, with participants in the same interest group. If a thread is moderated, questions are sent to a human moderator who screens the questions for appropriateness. Otherwise, questions are simply listed by topic. Most threads are archived by date.

Newsgroup software employs the same information service modality as email, and in fact, is dependent upon email for its operational infrastructure. Newsgroup facilities are also available through most information service portals, such as America Online and Google. With Google, you can access newsgroups via http://groups.google.com.

\section{QUICK SUMMARY}

1. The subject of services is important to most people because they are employed in services and are also consumers of services. In the year 2000, U.S. service employment comprised $80 \%$ of the workforce. Surprisingly, very little attention is given to the service sector, in spite of the fact that most of us work in it.

2. A service is a provider/client interaction that creates and captures value. A unique characteristic of services, unlike agriculture and manufacturing, is that both parties participate in the transaction, and in the process, both capture value. In a sense, the provider and the client co-produce the service event, because one can't do without the other.

3. There are several definitive characteristics of services. They are summarized as follows. A service is a process. A service is heterogeneous. A service captures value. A service cannot be inventoried. A service is intangible. A service is consumed at the point of production. A service cannot be resold or given away. And finally, a service is co-produced.

4. A service system is a system of people and technology that adapts to the changing value of knowledge in the system. The participants in a service system are the provider and client and the relationship between them is the service process. Systems of this type require an environment in which to operate that can take the form of a service factory in which the client resides for the duration of the service process and the service shop in which a possession of the client resides for the duration of the service event.

5. Service systems are facilitated by information and communications technology and enhanced by globalization. Service provisioning is inherent in outsourcing and offshoring. Innovation in supplying services is required because services are usually customized and labor intensive.

6. Core business processes are not customarily outsourced, and outsourcing predominantly does not provide differentiation in the marketplace.

7. An information service is a resource capable of supporting a service event or instantiating in a service event based on information. In other words, an information service can assist in the execution of a service, such as in retailing, or it can actually be the service as when buying a pair of shoes on the Internet

8. Most of the information that is communicated between people is about something. With information services, the client requests information and the provider supplies it using some form of communications channel.

9. Software would appear to be a service, such as in document preparation and as suggested by the example of ordinary mail. Information is moved from one placed to another and perhaps it is transformed a bit in the process. 
10. Information is the cornerstone of modern business, and government as well, and is the major ingredient in everyday commerce. Business information services are usually divided into two categories: operational services and management services. Operational services are employed to run the enterprise and management services are used to manage the enterprise.

11. Teams are the accepted norm in the modern enterprise, and collaboration is the process by which they progress toward a common goal. With information services, collaboration between groups and individuals can be effected from geographically dispersed locations.

12. Major enterprise information service applications are electronic commerce, electronic business, and electronic government. Major personal information service applications are chat rooms, instant messaging, Internet telephone, web auctions, web logs, podcasts, RSS feeds, social networking, and newsgroups.

\section{ACKNOWLEDGMENT}

Thanks to William Dowling, H. Choi, and Margaret Katzan for reading the manuscript.

\section{REFERENCES}

1. Friedman, T.L. (2006), The World is Flat: A Brief History of the Twenty-First Century, New York: Farrar, Straus and Giraux.

2. $\quad$ Gralla, P. (2004), How the Internet Works, Indianapolis, IN: Que Publishing.

3. Hagel, J. and J.S. Brown (2007), From Push to Pull: Emerging Models for Mobilizing Resources, www.edgeperspectives.com.

4. IBM Almaden Services Research (2006), Service Science, Management, and Engineering (SSME): Challenges, Frameworks, and Call for Participation, http://almaden.ibm.com/ssme, p. 13.

5. $\quad$ IBM Almaden Services Research (2006), SSME: What are services? http://almaden.ibm.com/ssme.

6. Katzan, H. (2008), Event Differentiation in Service Science, Journal of Business and Economics Research, Volume 6, Number 5 (May 2008), pp 141-151.

7. Katzan, H. (2008), Service Science: Concepts, Technology, Management (in press).

8. Maglio, P.P. (2007), Service Science, Management, and Engineering (SSME): An Interdisciplinary Approach to Service Innovation, IBM Almaden Research Center, http://almaden.ibm.com/ssme, p. 14.

9. Maglio, P.P. and J. Spohrer (2007), Fundamentals of Service Science, IBM Almaden Research Center.

10. Offshoring (2007), http://en.wikipedia.org/wiki/Offshoring.

11. Ontology (2007), http://en.wikipedia.org/wiki/Ontology.

12. Outsourcing (2007), http://en.wikipedia.org/wiki/Outsourcing.

13. Richardson, L. and S. Ruby (2007), RESTful Web Services, Sebastopol, DA; O'Reilly Media, Inc.

14. Sporer, J. Maglio, P., Bailey, J. and D. Gruhl (2007), Steps Toward a Science of Service Systems, IBM Almaden Research Center, San Jose, CA, www.almaden.ibm.com/asr, 2007.

15. Spohrer, J., Vargo, S.C., Caswell, N., and P.P. Maglio (2007), The Service System is the Basic Abstraction of Service Science, IBM Research, Almaden Research Center, San Jose, CA, www.almaden.ibm.com/asr.

16. Stair, R.M. and G.W. Reynolds (2008), Principles of Information Systems: A Managerial Approach, Boston: Thomson Course Technology.

17. Tabas, L. (2007), Designing for Service Systems, UCB iSchool Report 2007-008, February, 2007.

18. Tapscott, D. and A.D. Williams (2006), Wikinomics: How Mass Collaboration Changes Everything, New York: Penguin Group, Inc..

19. Tidwell, J. (2006), Designing Interfaces, Sebastopol, CA: O'Reilly Media, Inc.

20. Vargo, S. and B. Lusch (2004), Evolving to a New Dominant Logic for Marketing, Journal of Marketing, 69 (January, 2004), 1-17.

21. Vargo, S. and B. Lusch (2007), Service-Dominant Logic Basics, www.sdlogic.net. 